\title{
Relationship Between Ambulatory Blood Pressure and Aortic Arch Atherosclerosis
}

\author{
Shinichi Iwata, MD, PhDa, Zhezhen Jin, PhD ${ }^{\mathrm{b}}$, Joseph E Schwartz, PhD ${ }^{\mathrm{a}} \mathrm{c}$, Shunichi \\ Homma, MD ${ }^{a}$, Mitchell S.V. Elkind, MD ${ }^{d}$, Tatjana Rundek, MD, PhD ${ }^{e}$, Ralph L. Sacco, MD, \\ MS $^{e, f}$, and Marco R. Di Tullio, MD ${ }^{a}$ \\ aDepartment of Medicine, Columbia University, New York, NY, USA \\ ${ }^{b}$ Department of Biostatistics, Columbia University, New York, NY, USA \\ 'Department of Psychiatry and Behavioral Sciences, Stony Brook University, Stony Brook, NY, \\ USA \\ dDepartment of Neurology, Columbia University, New York, NY, USA \\ eDepartment of Neurology, University of Miami, Miami, FL, USA \\ fDepartment of Epidemiology and Human Genetics, University of Miami, Miami, FL, USA
}

\begin{abstract}
Objective-Atherosclerotic plaque in the aortic arch is an independent risk factor for ischemic stroke. Although high blood pressure (BP) measured at the doctor's office is known to be associated with aortic atherosclerosis, little is known on the association between 24-hour ambulatory BP and aortic arch plaque presence and severity. Our objective was to clarify the association between ambulatory BP variables and aortic arch atherosclerosis in a communitybased cohort.
\end{abstract}

Methods-The study population consisted of 795 patients (mean age $71 \pm 9$ years) participating in the Cardiovascular Abnormalities and Brain Lesions (CABL) study who underwent 24-hour ambulatory BP monitoring (ABPM). Arch plaque was evaluated by $2 \mathrm{D}$ transthoracic echocardiography from a suprasternal window.

Results-All systolic ABPM variables (24-hour/daytime/nighttime mean systolic BP, daytime/ nighttime systolic BP variability) were associated with the presence of any plaque and large $(\geq 4 \mathrm{~mm})$ plaque, whereas diastolic BP variables were not associated with aortic atherosclerosis. Multiple regression analysis indicated that nighttime systolic BP variability (expressed as the standard deviation of nighttime systolic BP) remained independently associated with large plaque after adjustment for age, sex, cigarette smoking, history of hypertension, diabetes mellitus, hypercholesterolemia, anti-hypertensive medication and nighttime mean systolic BP (odds ratio 1.39 per 1 standard deviation increase, $95 \%$ CI 1.00 to $1.93, \mathrm{P}<0.05)$.

(c) 2012 Elsevier Ireland Ltd. All rights reserved.

Corresponding author: Marco R. Di Tullio md42@columbia.edu Columbia University, College of Physicians and Surgeons, 630 W $168^{\text {th }}$ St, New York, NY 10032, USA Tel: 1-212-305-9875, Fax: 1-212-342-6051.

Publisher's Disclaimer: This is a PDF file of an unedited manuscript that has been accepted for publication. As a service to our customers we are providing this early version of the manuscript. The manuscript will undergo copyediting, typesetting, and review of the resulting proof before it is published in its final citable form. Please note that during the production process errors may be discovered which could affect the content, and all legal disclaimers that apply to the journal pertain.

Disclosure Summary: The authors have nothing to disclose. 
Conclusion-Systolic ABPM variables are significantly associated with the presence of arch plaque. Nighttime systolic BP variability is independently associated with large arch plaque. These findings may have important implications in gaining further insights into the mechanism of arch plaque formation and progression.

\section{Keywords}

ambulatory blood pressure; aortic arch atherosclerosis; blood pressure variability

\section{Introduction}

The presence of aortic arch plaque is a risk factor for ischemic stroke. The association between aortic arch plaque and stroke risk, initially established in autopsy studies ${ }^{1}$, has subsequently been confirmed by in-vivo studies that used transesophageal echocardiography with a case-control ${ }^{2}$ or prospective ${ }^{3-5}$ design. Large plaques (defined as $\geq 4 \mathrm{~mm}$ in most studies) were proven to increase the risk of first stroke ${ }^{1-3}$, recurrent stroke ${ }^{4}$ and death ${ }^{6}$. The presence of aortic arch plaque is related to the traditional risk factors for atherosclerosis, such as age ${ }^{3}$, hypertension ${ }^{7}$, hypercholesterolemia ${ }^{8}$, smoking $^{9}$, and to newer ones such as hyperhomocysteinemia ${ }^{10}$. Also, local hemodynamic factors such as oscillatory shear stress, which may facilitate plaque rupture and subsequent thrombus formation, may be associated with plaque progression ${ }^{11,12}$.

Ambulatory blood pressure monitoring (ABPM) provides information that is not obtained from conventional office-based blood pressure (BP) measurements, and is also more reproducible ${ }^{13}$. Several studies have shown that target organ damage ${ }^{14}$ and prognosis ${ }^{15}$ are more closely associated with ambulatory BP than with casual BP measured in the doctor's office. Moreover, diminished nocturnal BP decline ${ }^{16}$ and increased 24-hour BP variability ${ }^{17}$, which can only be evaluated by ABPM, are associated with subsequent cardiovascular events and cardiovascular mortality. However, the association between ABPM variables and aortic arch plaque has not been elucidated in properly sized clinical studies.

The aim of the present study was therefore to assess the relationship between aortic arch plaques and ABPM variables (24-hour/daytime/nighttime mean value and variability; nocturnal decline), and to assess the relationship between plaque size and BP variability (which may reflect oscillatory shear stress and therefore be related to plaque progression) in an unselected sample of the general population.

\section{Methods}

\section{Study population}

This study was conducted at Columbia University Medical Center. The study sample was derived from the National Institutes of Neurological Disorders and Stroke (NINDS)sponsored Cardiac Abnormalities and Brain Lesions (CABL) study, whose aim is to assess the relationship between subclinical cardiovascular disease and silent brain infarctions in a community-based cohort. Participants were drawn from the Northern Manhattan Study (NOMAS), an epidemiologic study carried out in New York City. Extensive details about the population and enrollment of NOMAS have been published previously ${ }^{18}$. Briefly, subjects were eligible if they (1) had never been diagnosed with stroke, (2) were aged $\geq 50$ years, and (3) resided in northern Manhattan for $\geq 3$ months in a household with a telephone. The study was approved by the institutional review board of Columbia University Medical Center, and informed consent was obtained from all study participants. Cardiovascular risk factors were ascertained through direct examination and interview by trained research assistants. Among the variables used in the analysis, hypertension was defined as systolic 
blood pressure (SBP) $\geq 140 \mathrm{mmHg}$ or diastolic blood pressure (DBP) $\geq 90 \mathrm{mmHg}$ (mean of two readings) or a patient's self-reported history of hypertension or antihypertensive medication use. Diabetes mellitus was defined by the patient's self-report of such a history and/or current use of insulin or hypoglycemic agents, or a fasting glucose of $>126 \mathrm{mg} / \mathrm{dl}$, tested at least twice at different times in each participant. Smoking status was defined as cigarette smoking at any time in the past or present. Hypercholesterolemia was defined as total serum cholesterol $>240 \mathrm{mg} / \mathrm{dl}$, a patient's self-report of hypercholesterolemia or presence of lipid-lowering treatment.

\section{Detection of Aortic Plaques}

Two dimensional transthoracic images of the aortic arch with real time 3D confirmation from a suprasternal window were obtained by a registered cardiac sonographer following a standardized protocol using a commercially available system (iE33; Philips Medical Systems, Andover, MA) equipped with a 2.5-MHz to 3.5-MHz transducer. All the tests were stored on digital media for subsequent analysis. The aortic arch was defined as the portion of aorta between the curve at the end of the ascending portion and the takeoff of the left subclavian artery. A plaque was defined as a discrete protrusion of the intimal surface of the vessel at least $1 \mathrm{~mm}$ in thickness, different in appearance and echogenicity from the adjacent intact intimal surface (Figure, arrow). Plaques were classified as small $(<4 \mathrm{~mm})$ or large $(\geq 4 \mathrm{~mm})$. In case of multiple plaques, the most advanced lesion was considered. All images were interpreted by a single experienced echocardiographer (MDT) blinded to subject's characteristics and risk factors.

\section{Ambulatory Blood Pressure Assessment}

An ambulatory blood pressure monitor (SpaceLabs Model 90207, Redmond, WA) was used to assess 24-hour BP as the subjects performed their normal activities. The accuracy and reliability of the device have been previously validated according to the Association for the Advancement of Medical Instrumentation criteria ${ }^{19}$. ABPM was performed according to previously published protocols with a BP cuff appropriately sized to arm circumference and placed on the subject's non-dominant arm. The monitor was set to automatically record BP at 15-minute intervals during awake hours and 30-minute intervals during sleep hours. Before use, the device was calibrated against a reference mercury manometer; criterion for target agreement was within $\pm 5 \mathrm{mmHg}$. Recordings were retrieved and analyzed with the aid of ambulatory BP report management system software (SpaceLabs Systems, 2004). The average SBP/DBP obtained by ambulatory BP assessment were calculated for a 24-hour period and separately for awake and sleep periods, which were determined using the subject's diary reports of actual sleep and awake times. BP variability was calculated as the SDs of mean awake and asleep SBP/DBP. The percent decline in nocturnal SBP/DBP was calculated as (awake SBP/DBP - asleep SBP/DBP) $\times 100 /$ awake SBP/DBP ${ }^{16}$. Clinic BP was the average of two measurements in sitting position taken by a research assistant using a mercury sphygmomanometer and BP cuff appropriately sized to arm circumference.

\section{Statistical analysis}

Statistical analysis was performed using SAS software version 9.1 (SAS Institute Inc, Cary, $\mathrm{NC})$. Continuous variables are expressed as mean value $\pm \mathrm{SD}$. Multiple logistic regression analysis adjusted for age, male sex, cigarette smoking, hypertension, hypercholesterolemia, diabetes mellitus (which are risk factors for aortic arch plaque), and for anti-hypertensive medication use (which influences ABPM variables) was carried out to identify the independent predictors of aortic arch plaque. In addition to these covariates, we adjusted for daytime/nighttime mean SBP/DBP levels in the analyses for BP variability, and for 24-hour mean BP in the analyses for nocturnal BP decline. A p value of $<0.05$ was considered statistically significant for all tests. 


\section{Results \\ Study Cohort}

A total of 1004 participants were enrolled in CABL, but 169 did not have ABPM because of refusal (155) or inability to complete the test (14). This left 835 participants with ABPM data, out of which incomplete information on arch plaque or insufficient ABPM data points were observed in 40 , leaving a final sample size of 795 . Clinical characteristics of the study cohort and ABPM findings are shown in Table 1. Aortic arch plaques of any size were found in 578 subjects $(73 \%)$, large $(\geq 4 \mathrm{~mm})$ aortic arch plaques in 85 subjects $(11 \%)$.

Univariate predictors of aortic arch plaque-Table 2 shows the variables associated with the presence of any and large aortic arch plaque. Age, hypertension, presence of plaque at the carotid bifurcation and all SBP variables were univariate predictors of any plaque and large plaque. Cigarette smoking and anti-hypertensive medication use were associated with a borderline increase in the risk of any plaque, and a significant risk of large plaque. SBP nocturnal decline was only associated with large plaque. DBP variables were not associated with arch atherosclerosis.

\section{ABPM predictors of any plaque and large plaque in the aortic arch - Multivariable analysis-Table 3 shows the ABPM variables associated with the presence of any and large $(\geq 4 \mathrm{~mm})$ aortic arch plaque and their adjusted odds ratio obtained by multiple logistic regression analysis. 24-hour mean SBP and SBP daytime variability were associated with a borderline increase in risk of any plaque. Nighttime SBP variability remained independently associated with large plaque after adjustment for differences in age, sex, smoking status and history of hypertension, diabetes mellitus, hypercholesterolemia, anti-hypertensive medication use, and mean nighttime SBP (odds ratio 1.39 per 1standard deviation increase, $95 \%$ CI 1.00 to $1.93, \mathrm{P}<0.05)$.}

\section{Discussion}

In the present study, we observed that all systolic ABPM variables were significantly associated with the presence of plaques of any size and large plaques in the aortic arch. Moreover, nighttime SBP variability was a predictor of the presence of large plaques, which carry an increased stroke risk, after adjustment for accepted atherosclerotic risk factors and for nighttime mean SBP. DBP variables and a blunted nocturnal decline in both systolic and diastolic BP were not found to predict any plaque or large plaque in multivariable analyses. These results suggest that SBP may be important for plaque formation, and that marked fluctuations of SBP during sleep may be of importance for plaque progression. To the best of our knowledge, this is the first study to demonstrate that nighttime SBP variability is associated with the presence of large plaques in the aortic arch in the general population. There is growing evidence that nighttime BP is a better predictor of cardiovascular outcome than daytime $\mathrm{BP}^{20,21}$. The mechanisms that underlie this difference remain poorly understood. There is, however, considerable evidence suggesting that sleeping has a buffering effect on the adverse consequences of physical and mental stress by reducing neuroendocrine activity and sympathetic stimulation. Therefore, nighttime BP is not subject to confounding factors such as physical and mental stress, and reflects the patient's intrinsic $\mathrm{BP}$ characteristics better than daytime BP.

Local hemodynamic factors affect the occurrence of atherosclerosis. Shear stress, the drag force acting on the vessel wall associated with blood flow, plays an important role in the development of endothelial dysfunction and atherosclerosis ${ }^{11}$. Oscillatory shear stress causes a sustained activation of pro-oxidant processes (i.e., NADH oxidase) resulting in redox-sensitive gene expression (i.e., redox-sensitive gene heme oxygenase-1) in human 
endothelial cells, which may induce plaque formation ${ }^{22}$. High BP variability is assumed to change the blood flow characteristics, increasing the effects of low shear stress and oscillatory shear stress. Consequently, exaggerated BP variability may produce injury to the blood vessels, possibly facilitating plaque rupture. Sudden plaque rupture, thrombus formation, and subsequent incorporation of thrombus into the atherosclerotic plaque are known to cause rapid progression of atherosclerosis ${ }^{12}$. We have previously reported that the coexistence of a hypercoagulable state in patients with aortic arch plaque may increase the likelihood of superimposed thrombus formation and further enhance the embolic potential of the plaque ${ }^{23}$. The findings of the present study may suggest that nighttime SBP variability may have an effect on the atherosclerotic process in the aortic arch. This finding is consistent with a previous study that showed that nighttime SBP variability was an independent risk factor for stroke ${ }^{24}$ and carotid plaque ${ }^{25}$. The Stroke Prevention: Assessment of Risk in a Community (SPARC) ${ }^{7}$ study, which did not provide data on BP nocturnal dipping status and on BP variability, reported that daytime and nighttime SBP were associated with both any and large plaque, while daytime and nighttime DBP were not. These results are consistent in part with ours, although only nighttime SBP variability was associated with large plaque in our study. This difference might stem in part from different study cohorts, and from the more complete set of atherosclerotic risk factors adjusted for in our analysis (age, male sex, cigarette smoking, hypertension, hypercholesterolemia, diabetes mellitus and anti-hypertensive medication use in our study, versus only age and cigarette smoking in SPARC).

Some studies observed a significantly better prognosis in patients with a greater nocturnal $\mathrm{BP}$ decline ${ }^{26}$, but this was not confirmed by others ${ }^{27}$. Thus, the role of nocturnal decline as a risk factor for cardiovascular events is still controversial. Our study showed no association between nocturnal BP decline (a continuous measure) or normal BP dipping status (a binary variable) and either any or large arch plaque.

Our study has some limitations. First, cross-sectional data cannot investigate causality. Prospective studies would be necessary to assess whether BP variables indeed predict aortic arch plaque progression. Second, given the relatively small number of large plaques, we could not compare the relationship between BP and arch atherosclerosis across different race/ethnic groups. Third, because our data were obtained with transthoracic echocardiography, we may have underestimated the prevalence of plaques, and could not accurately evaluate plaque morphology (i.e., presence of ulceration or small mobile components), which has been linked to increased embolic risk ${ }^{1,5}$ and requires transesophageal echocardiography or MRI (currently the best way to image vulnerable plaques) for a more accurate analysis. However, transthoracic echocardiography is a noninvasive technique that is better suited for use in asymptomatic individuals, and has been proven to be accurate for detection of aortic plaques, especially large ones ${ }^{28,29}$. Positive and negative predictive values for large aortic plaque by comparison with transesophageal echocardiography were reported at $91 \%$ and $98 \%$, respectively ${ }^{30}$. Moreover, in our study we confirmed the presence of plaques with real time 3D imaging, which added to the completeness of the examination.

\section{Conclusions}

Systolic ABPM variables are significantly associated with the presence of aortic arch plaque, and nighttime systolic BP variability is independently associated with large plaques, which carry a greater stroke risk. These findings may have important implications in gaining further insights into the mechanism of arch plaque progression. The hypothesis that nighttime SBP variability is associated with accelerated plaque progression requires further investigation. 


\section{Abbreviations}

$\begin{array}{ll}\text { ABPM } & \text { ambulatory blood pressure monitoring } \\ \text { BP } & \text { blood pressure } \\ \text { SBP } & \text { systolic blood pressure } \\ \text { DBP } & \text { diastolic blood pressure }\end{array}$

\section{Acknowledgments}

This study was supported by R01 NS36286 from the National Institute of Neurological Disorders and Stroke (NINDS).

\section{References}

1. Amarenco P, Duyckaerts C, Tzourio C, Henin D, Bousser MG, Hauw JJ. The prevalence of ulcerated plaques in the aortic arch in patients with stroke. N Engl J Med. 1992; 326:221-225. [PubMed: 1727976]

2. Di Tullio MR, Sacco RL, Gersony D, Nayak H, Weslow RG, Kargman DE, Homma S. Aortic atheromas and acute ischemic stroke: A transesophageal echocardiographic study in an ethnically mixed population. Neurology. 1996; 46:1560-1566. [PubMed: 8649549]

3. Tunick PA, Rosenzweig BP, Katz ES, Freedberg RS, Perez JL, Kronzon I. High risk for vascular events in patients with protruding aortic atheromas: A prospective study. J Am Coll Cardiol. 1994; 23:1085-1090. [PubMed: 8144773]

4. Atherosclerotic disease of the aortic arch as a risk factor for recurrent ischemic stroke. The french study of aortic plaques in stroke group. N Engl J Med. 1996; 334:1216-1221. [PubMed: 8606716]

5. Mitusch R, Doherty C, Wucherpfennig H, Memmesheimer C, Tepe C, Stierle U, Kessler C, Sheikhzadeh A. Vascular events during follow-up in patients with aortic arch atherosclerosis. Stroke. 1997; 28:36-39. [PubMed: 8996485]

6. Di Tullio MR, Russo C, Jin Z, Sacco RL, Mohr JP, Homma S. Aortic arch plaques and risk of recurrent stroke and death. Circulation. 2009; 119:2376-2382. [PubMed: 19380621]

7. Agmon Y, Khandheria BK, Meissner I, Schwartz GL, Petterson TM, O'Fallon WM, Gentile F, Whisnant JP, Wiebers DO, Seward JB. Independent association of high blood pressure and aortic atherosclerosis: A population-based study. Circulation. 2000; 102:2087-2093. [PubMed: 11044425]

8. Matsuzaki M, Ono S, Tomochika Y, Michishige H, Tanaka N, Okuda F, Kusukawa R. Advances in transesophageal echocardiography for the evaluation of atherosclerotic lesions in thoracic aorta--the effects of hypertension, hypercholesterolemia, and aging on atherosclerotic lesions. Jpn Circ J. 1992; 56:592-602. [PubMed: 1625364]

9. Inoue T, Oku K, Kimoto K, Takao M, Nomoto J, Handa K, Kono S, Arakawa K. Relationship of cigarette smoking to the severity of coronary and thoracic aortic atherosclerosis. Cardiology. 1995; 86:374-379. [PubMed: 7585737]

10. Sen S, Oppenheimer SM, Lima J, Cohen B. Risk factors for progression of aortic atheroma in stroke and transient ischemic attack patients. Stroke. 2002; 33:930-935. [PubMed: 11935039]

11. Cheng C, Tempel D, van Haperen R, van der Baan A, Grosveld F, Daemen MJ, Krams R, de Crom R. Atherosclerotic lesion size and vulnerability are determined by patterns of fluid shear stress. Circulation. 2006; 113:2744-2753. [PubMed: 16754802]

12. Zaman AG, Helft G, Worthley SG, Badimon JJ. The role of plaque rupture and thrombosis in coronary artery disease. Atherosclerosis. 2000; 149:251-266. [PubMed: 10729375]

13. James GD, Pickering TG, Yee LS, Harshfield GA, Riva S, Laragh JH. The reproducibility of average ambulatory, home, and clinic pressures. Hypertension. 1988; 11:545-549. [PubMed: 3384470]

14. Mancia G, Parati G. Ambulatory blood pressure monitoring and organ damage. Hypertension. 2000; 36:894-900. [PubMed: 11082163] 
15. Ohkubo T, Hozawa A, Nagai K, Kikuya M, Tsuji I, Ito S, Satoh H, Hisamichi S, Imai Y. Prediction of stroke by ambulatory blood pressure monitoring versus screening blood pressure measurements in a general population: The ohasama study. J Hypertens. 2000; 18:847-854. [PubMed: 10930181]

16. Ohkubo T, Hozawa A, Yamaguchi J, Kikuya M, Ohmori K, Michimata M, Matsubara M, Hashimoto J, Hoshi H, Araki T, Tsuji I, Satoh H, Hisamichi S, Imai Y. Prognostic significance of the nocturnal decline in blood pressure in individuals with and without high 24-h blood pressure: The ohasama study. J Hypertens. 2002; 20:2183-2189. [PubMed: 12409956]

17. Sander D, Kukla C, Klingelhofer J, Winbeck K, Conrad B. Relationship between circadian blood pressure patterns and progression of early carotid atherosclerosis: A 3-year follow-up study. Circulation. 2000; 102:1536-1541. [PubMed: 11004145]

18. White H, Boden-Albala B, Wang C, Elkind MS, Rundek T, Wright CB, Sacco RL. Ischemic stroke subtype incidence among whites, blacks, and hispanics: The northern manhattan study. Circulation. 2005; 111:1327-1331. [PubMed: 15769776]

19. O'Brien E, Coats A, Owens P, Petrie J, Padfield PL, Littler WA, de Swiet M, Mee F. Use and interpretation of ambulatory blood pressure monitoring: Recommendations of the british hypertension society. BMJ. 2000; 320:1128-1134. [PubMed: 10775227]

20. Dolan E, Stanton A, Thijs L, Hinedi K, Atkins N, McClory S, Den Hond E, McCormack P, Staessen JA, O'Brien E. Superiority of ambulatory over clinic blood pressure measurement in predicting mortality: The dublin outcome study. Hypertension. 2005; 46:156-161. [PubMed: 15939805]

21. Fagard RH, Celis H, Thijs L, Staessen JA, Clement DL, De Buyzere ML, De Bacquer DA. Daytime and nighttime blood pressure as predictors of death and cause-specific cardiovascular events in hypertension. Hypertension. 2008; 51:55-61. [PubMed: 18039980]

22. De Keulenaer GW, Chappell DC, Ishizaka N, Nerem RM, Alexander RW, Griendling KK. Oscillatory and steady laminar shear stress differentially affect human endothelial redox state: Role of a superoxide-producing nadh oxidase. Circ Res. 1998; 82:1094-1101. [PubMed: 9622162]

23. Di Tullio MR, Homma S, Jin Z, Sacco RL. Aortic atherosclerosis, hypercoagulability, and stroke the apris (aortic plaque and risk of ischemic stroke) study. J Am Coll Cardiol. 2008; 52:855-861. [PubMed: 18755350]

24. Pringle E, Phillips C, Thijs L, Davidson C, Staessen JA, de Leeuw PW, Jaaskivi M, Nachev C, Parati G, O'Brien ET, Tuomilehto J, Webster J, Bulpitt CJ, Fagard RH. Systolic blood pressure variability as a risk factor for stroke and cardiovascular mortality in the elderly hypertensive population. J Hypertens. 2003; 21:2251-2257. [PubMed: 14654744]

25. Shintani Y, Kikuya M, Hara A, Ohkubo T, Metoki H, Asayama K, Inoue R, Obara T, Aono Y, Hashimoto T, Hashimoto J, Totsune K, Hoshi H, Satoh H, Imai Y. Ambulatory blood pressure, blood pressure variability and the prevalence of carotid artery alteration: The ohasama study. $\mathrm{J}$ Hypertens. 2007; 25:1704-1710. [PubMed: 17620969]

26. Verdecchia P, Porcellati C, Schillaci G, Borgioni C, Ciucci A, Battistelli M, Guerrieri M, Gatteschi C, Zampi I, Santucci A, et al. Ambulatory blood pressure. An independent predictor of prognosis in essential hypertension. Hypertension. 1994; 24:793-801. [PubMed: 7995639]

27. Khattar RS, Swales JD, Dore C, Senior R, Lahiri A. Effect of aging on the prognostic significance of ambulatory systolic, diastolic, and pulse pressure in essential hypertension. Circulation. 2001; 104:783-789. [PubMed: 11502703]

28. Hussein A, Hilal D, Hamoui O, Hussein H, Abouzahr L, Kabbani S, Chammas E. Value of aortic arch analysis during routine transthoracic echocardiography in adults. Eur J Echocardiogr. 2009; 10:625-629. [PubMed: 19246499]

29. Couturier G, Voustaniouk A, Weinberger J, Fuster V. Correlation between coronary artery disease and aortic arch plaque thickness measured by non-invasive b-mode ultrasonography. Atherosclerosis. 2006; 185:159-164. [PubMed: 16023654]

30. Schwammenthal E, Schwammenthal Y, Tanne D, Tenenbaum A, Garniek A, Motro M, Rabinowitz B, Eldar M, Feinberg MS. Transcutaneous detection of aortic arch atheromas by suprasternal harmonic imaging. J Am Coll Cardiol. 2002; 39:1127-1132. [PubMed: 11923035] 


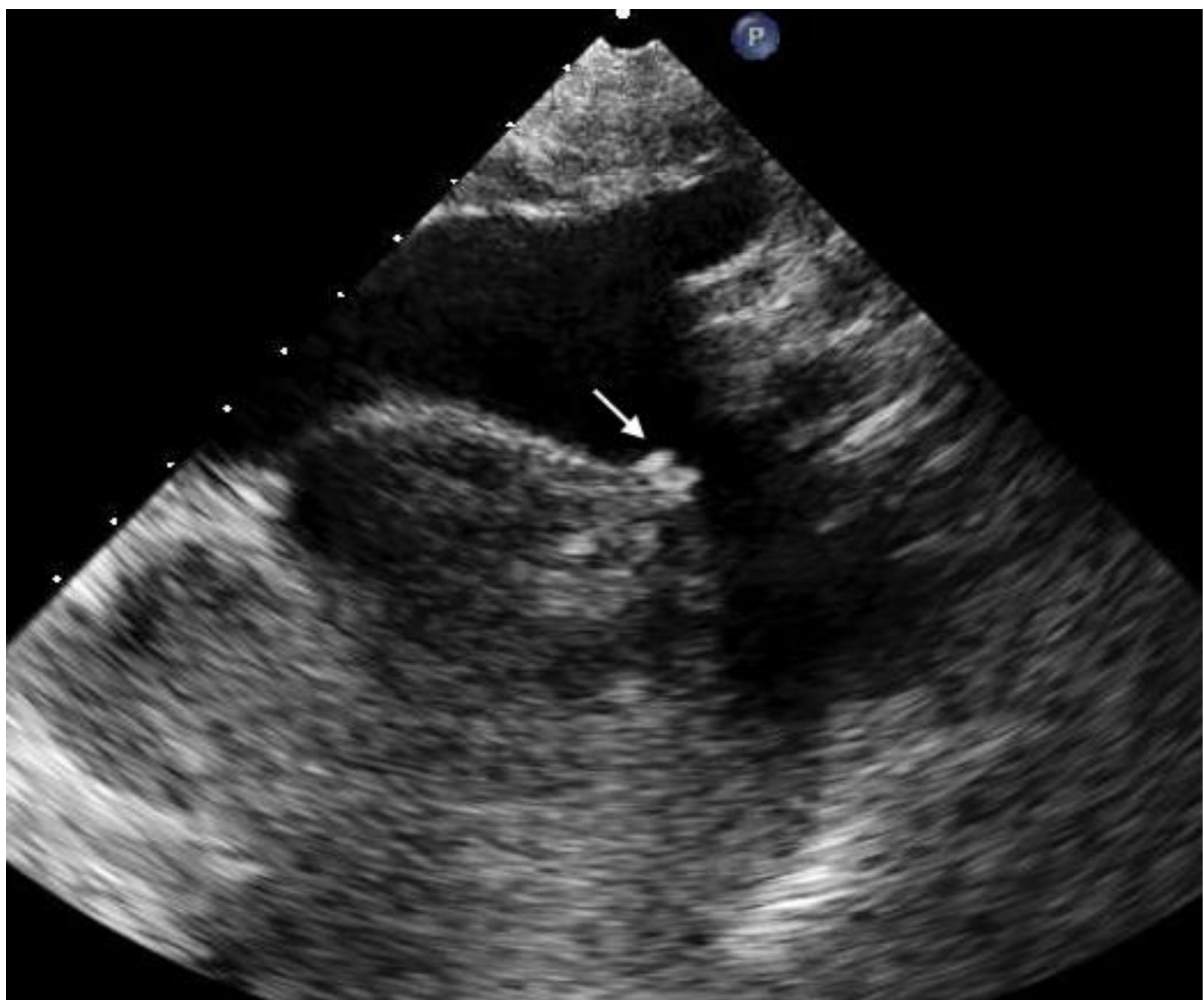

Figure 1.

Two-dimensional image from a suprasternal window of a large atherosclerotic plaque (arrow) in the distal portion of the aortic arch. 


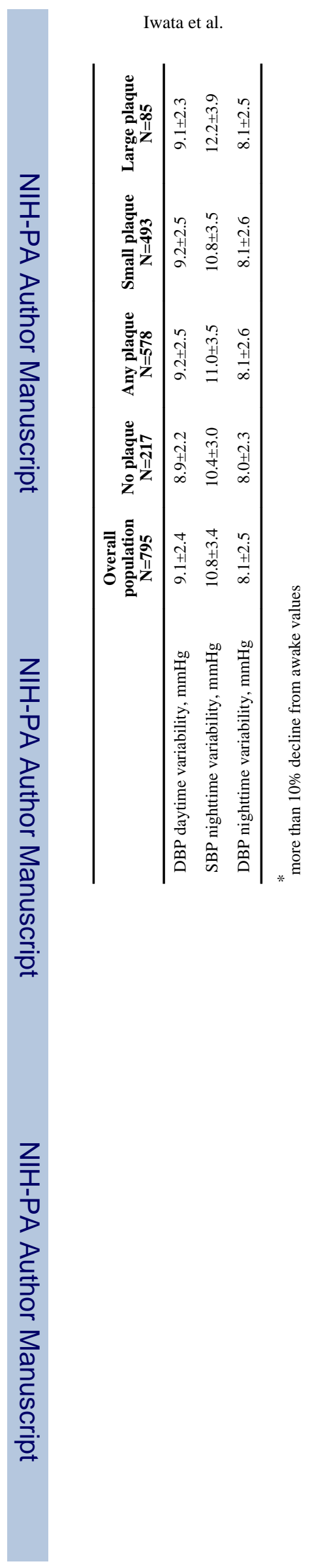

Page 10 
